\title{
Potencial informativo dos sítios abrigados do Estado de São Paulo: Abrigo do Alvo e Abrigo de Itapeva
}

\author{
Letícia Cristina Correa, Tatiane de Souza \\ Universidade de São Paulo. Av. Prof. Almeida Prado, 1466, Butantã, São Paulo, 05508-070, Brasil. \\ Email: Correa: leticiacorrea@usp.br; Souza: tatiane_sza@yahoo.com.br
}

\begin{abstract}
Resumo:
O Estado de São Paulo é uma área propícia para a formação de carste. Tal fator é decorrente de suas características litológicas que favorecem a formação de cavernas e abrigos em arenito e calcário. Seja por espeleólogos ou arqueólogos, muitos sítios arqueológicos em contextos abrigados são detectados no interior paulista, no entanto, seus estudos ainda são pouco aprofundados. Neste artigo apresentaremos resultados preliminares dos sítios Abrigo do Alvo localizando em Analândia com a cronologia mais recente estabelecida em 970 anos cal AP e a mais antiga em 7.500 anos cal AP; e o sítio Abrigo do de Itapeva, no município homônimo com ocupações que vão de 585 anos cal AP até 5.858 anos cal AP. Ambos os abrigos apresentam vestígios arqueológicos similares: inscrições rupestres, material faunístico e artefatos líticos. A exceção ocorre no Abrigo de Itapeva que possui material cerâmico associado à Tradição Itararé e fragmentos de ossos humanos. Embora seja notável a diversidade de vestígios, trataremos somente das indústrias líticas que estão em processo de análise. A fim de se estabelecer comparações entre os conjuntos inicialmente procurou-se reconhecer características genéricas como matéria-prima, suporte, dimensões, etc., somados a isso os atributos tecnológicos foram observados a fim de se extrair informações sobre os lascamentos, sinais de uso e retoques. No final, os resultados nos permitiram concluir que embora esses grupos humanos habitassem o interior paulista durante o Holoceno médio, suas indústrias líticas mostram pouca similaridade apontando para normas culturais distintas.
\end{abstract}

Palavras-chave: São Paulo; Holoceno; sítios sob abrigos; líticos; tecnologia

\section{Introdução}

Assim como os sítios a céu aberto, os depósitos de sedimento dos abrigos rochosos também estão suscetíveis a alterações. Essas modificações podem ser causadas por ações geogênicas, biogênicas, além da atividade humana. No entanto, quando preservados, esses locais podem apresentar grande potencial informativo devido à alta concentração de material arqueológico, preservação de vestígios orgânicos e a estratigrafia pode representar períodos de ocupação humana fornecendo uma história cultural da área (Araujo 2008).

No Estado de São Paulo, as pesquisas realizadas em sítios arqueológicos em contexto de abrigo aconteceram de maneira pontual, sendo poucos os que tiveram algum trabalho

Published by the School of History, Classics and Archaeology, University of Edinburgh ISSN: 2055-0472. URL: http://journals.ed.ac.uk/lithicstudies/

This work is licensed under a Creative Commons Attribution 2.5 UK: Scotland License. 
sistemático empregado. Durante os anos 1960 até meados de 1980 foram subaproveitados em detrimento a sítios céu aberto escavados a partir de superfícies amplas (Pallestrini1969; 1975; Pallestrini \& Chiara 1978; Vialou 1980; 1983).

Na década de 1970 (segundo documentação consultada no Museu da Cidade em Campinas- SP) o Abrigo de Itapeva teve sua pesquisa iniciada por Desidério Aytai que optou por realizar uma pequena intervenção abrindo duas quadras de escavação. Durante os anos de 1980 houve uma ênfase na arqueologia regional e os trabalhos de prospecção resultaram na detecção de sítios abrigados e sítios a céu aberto. No entanto, não foram realizadas escavações sistemáticas em abrigos (Araujo 2001). Também nessa época, outros abrigos rochosos foram identificados no Vale do Ribeira (Collet 1980; 1982; DeBlasis 1988; 1996; Robrahn 1988).

Na região de Rio Claro, a qual está inserida o Abrigo do Alvo, o levantamento de sítios abrigados teve seu início final da década de 1960. Diversos pesquisadores dedicaram parte de seus trabalhos na região (Altenfelder 1968; Miller 1969; Collet 1981; Caldarelli 1983). Esses estudos sistemáticos resultaram em informações que revelaram um alto potencial arqueológico da área.

Na década de 1970 a área de Analândia foi intensamente estudada por Collet e seu grupo de espeleólogos. A equipe prospectou a região com objetivo de localizar abrigos sob rocha e cavernas, lugares considerados por eles como sendo "sede de permanência e moradia de grupos Paleoíndios" (Collet 1994). Diversos abrigos foram detectados (Collet 1980; 1981; 1982), alguns sítios sofreram intervenções em seu piso, no entanto, sem a realização de uma escavação sistemática caraterística dos trabalhos arqueológicos.

Araujo (2012), dando continuidade aos trabalhos, vem realizando o levantamento sistemático e intervindo em abrigos já detectados, dando desse modo uma continuidade às pesquisas realizadas no interior paulista. As prospecções resultaram no cadastramento de mais dois sítios arqueológicos no Município de Analândia, ainda não foram escavados.

Neste artigo serão apresentados os dados preliminares que se referem aos sítios Abrigo do Alvo e Abrigo do Itapeva (Figura 1).

\section{Abrigo do Alvo}

O sítio arqueológico Abrigo do Alvo (ALV) está inserido na porção centro-leste do Estado de São Paulo, na região de Rio Claro, que atualmente possui os sítios mais antigos do estado (Araujo \& Correa 2016; Troncoso 2016). Localizado no Município de Analândia, foi identificado a partir de uma prospecção realizada pelo Grupo Bagrus de Espeleologia que buscavam mapear e cadastrar cavernas e abrigos rochosos na área de Analândia, esses trabalhos resultaram na detecção de sítios rupestres e líticos que se encontravam em um raio de $2 \mathrm{~km}$.

Guy Collet, responsável pelo grupo de espeleólogos, cadastrou o Abrigo do Alvo como sítio arqueológico em 1986. Em 2012, o arqueólogo Astolfo Araujo realizou a primeira escavação neste sítio, colocando fim a uma lacuna 30 anos sem escavações em abrigos no interior do Estado de São Paulo, desde a escavação do Abrigo Sarandi (Caldarelli 1983).

Dentre os sítios abrigados revisitados, o Abrigo do Alvo foi selecionado por apresentar gravuras geométricas que se assemelham à representação conhecida como "tridígitos". Essas figuras poderiam se remeter à Tradição Meridional de arte rupestre que se estende desde a Argentina até o centro do Estado de São Paulo (Prous 1991), sugerindo desse modo certa antiguidade.

\subsection{Contexto geológico e arqueológico}

O Município de Analândia está localizado entre as coordenadas $22^{\circ} 00^{\prime}$ e $22^{\circ} 15^{\prime}$ latitude S e $47^{\circ} 30^{\prime}$ e $47^{\circ} 50^{\prime}$ longitude $\mathrm{W}$, ocupando uma área de $325 \mathrm{~km}^{2}$ com altitude média de $680 \mathrm{~m}$. 
Encontra-se inserida parte na Depressão Periférica Paulista e no compartimento geomorfológico das Cuestas Arenito-basálticas (IPT 1981).

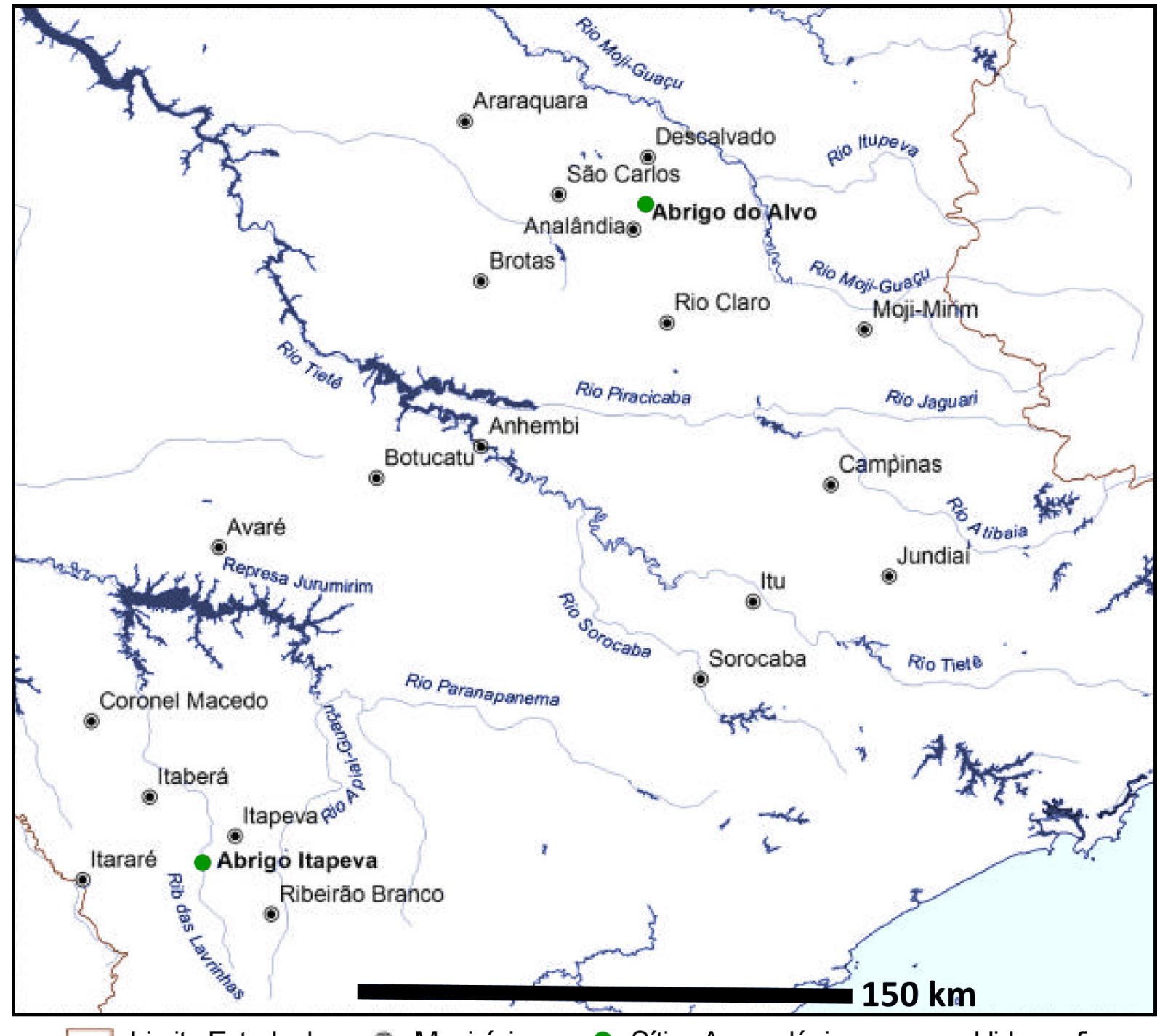

Limite Estadual

Município

Sítios Arqueológicos

Hidrografia

Figura 1: Mapa de localização dos sítios Abrigo de Itapeva e Abrigo do Alvo, São Paulo. Autora: Tatiane Souza. Figure 1. The Abrigo de Itapeva and Abrigo do Alvo sites location map, São Paulo State. Author: Tatiane Souza.

A delimitação entre a Depressão Periférica Paulista e as Cuestas Basálticas encontra-se marcadas por escarpas festonadas, atributo de um relevo em transição, caracterizado pela presença de anfiteatros separados por espigões de caimento abrupto, apresentando altos declives, acima de 30\% e com desníveis maiores que 100 metros, formando topos angulosos e vertentes com perfil retilíneos (Leite 2002: 35).

Na área correspondente à Depressão Periférica, predominam Latossolos VermelhoAmarelo e Neossolos Quartzarênicos. No front das cuestas a alta declividade favorece a formação de Neossolos Litólicos de textura argilosa. No topo e reverso da cuesta predominam Latossolos Vermelho-Escuro, Nitossolo e Latossolo Roxo (Ferreira 2005: 16).

A vegetação original era caracterizada, principalmente, por campos de cerrado e cerradões, constituída por uma cobertura herbácea mais ou menos contínua e um dossel descontínuo de elementos arbustivos, galhos retorcidos, cascas e folhas espessas (Ferreira 2005). 
Os solos passaram ao longo do tempo por um processo de modificação pouco restando do revestimento natural. Em muitos locais a vegetação primária foi substituída por culturas perenes, semi-perenes, silvicultura e pasto. As áreas que ainda abrigam a vegetação de cerrado relativamente preservada situam-se em altas declividades, como por exemplo, no front das cuestas e proximidades.

O abrigo é formado por um paredão rochoso de inclinação negativa no Arenito Botucatu, com aproximadamente $130 \mathrm{~m}^{2}$ e abertura voltada a Leste. Está localizado em meia encosta de morro e possui três painéis com registros rupestres compostos basicamente por gravuras, com alguns pontos marcados por pigmentos vermelhos. Essas gravuras se dividem em três painéis que totalizam $15 \mathrm{~m}$ de extensão por $2 \mathrm{~m}$ de altura.

Segundo Alberto (2013) as gravuras podem ser identificadas como bastonetes, linhas retas, paralelas, tridáctilos e cúpulas. Duas figuras circulares parecem estar associadas ao universo cultural humano, sendo representada uma ao lado da outra, diferenciando-se do restante dos registros e algumas são vestigiais, não sendo possível sua verificação (Figura 2).

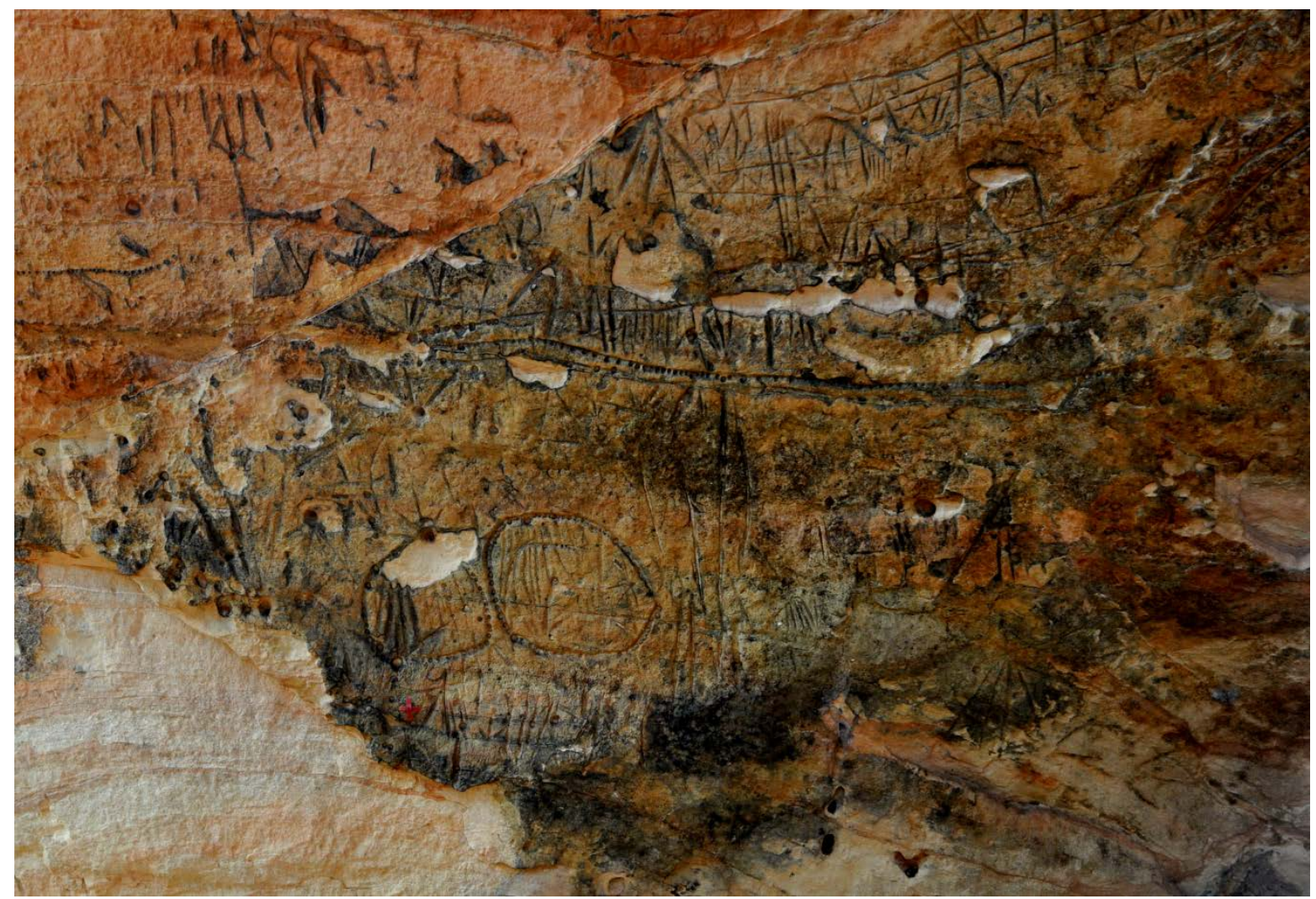

Figura 2: Gravuras rupestres do Sítio Abrigo do Alvo conforme descrito por Alberto (2013). Foto de Sílvia Cunha Lima (2012).

Figure 2. Rock engravings from Abrigo do Alvo, according to descriptions by Alberto (2013). Photo by Silvia Cunha Lima (2012).

No que se referem às datações, foram obtidas duas idades radiocarbônicas que podem apontar para duas ocupações (Tabela 1). A ocupação mais antiga teria ocorrido por volta de 7.500 cal AP. A amostra que resultou esta datação foi coletada na unidade J12 no nível 8, essa foi a unidade mais profunda da escavação. Já a amostra com a idade mais recente foi coletada na quadra E11 no nível 4.

No total foram escavadas seis unidades seguindo níveis artificiais acompanhados a cada $10 \mathrm{~cm}$. A decapagem foi feita com uma colher de pedreiro e todo o sedimento retirado das quadrículas foi peneirado. Após a escavação as unidades tiveram o sedimento devolvido. A 
plotagem dos vestígios arqueológicos coletados se deu por meio de uma estação total com coordenadas cartesianas X, Y e Z, sendo assim é possível reconstruir espacialmente a localização de todo material. Além do material lítico, compreendendo 116 peças, foram coletadas 130 amostras de carvão e 292 fragmentos de fauna.

Tabela 1. Amostras datadas de $\mathrm{C}^{14}$ para o sítio Abrigo do Alvo.

Table 1. $\mathrm{C}^{14}$ dated samples from the Abrigo do Alvo site.

\begin{tabular}{lccc}
\hline Amostra & Nível & Idade radiocarbônica convencional & Idade calibrada (2 sigma) \\
\hline Beta 318509 & 4 & $1140 \pm 30 \mathrm{AP}$ & 1170 a $1160 \mathrm{AP}$ \\
& & & 1140 a $1100 \mathrm{AP}$ \\
& & & 1100 a $970 \mathrm{AP}$ \\
Beta 318509 & 11 & $6530 \pm 40 \mathrm{AP}$ & 7500 a $7420 \mathrm{AP}$ \\
\hline
\end{tabular}

\section{Abrigo de Itapeva}

O Abrigo de Itapeva localiza-se no município homônimo, na porção sudeste do Estado de São Paulo. Além de muitos abrigos rupestres, nessa região também há registros de estruturas subterrâneas e montículos de terra, alguns desses sítios foram associados à Tradição Itararé e Tupiguarani (Prous 1979; Araujo 2001; Kamase 2004).

O abrigo foi inicialmente reconhecido por Araripe (1887) e desde o século XIX se destaca devido a suas inscrições rupestres. Na década de 1970, Desidério Aytai, além de realizar algumas intervenções no solo do abrigo, também elaborou um croqui no qual essas gravuras foram retratadas detalhadamente (Aytai 1970).

Posteriormente, nos anos de 1990 ele foi prospectado por Araujo (2001). A partir de 2015 começaram-se os trabalhos de escavações sistemáticas que já somam três etapas, e esses trabalhos resultaram em uma série de datações e materiais arqueológicos que estão em processo de análise, constituídos por lítico, cerâmica, material malacológico, ossos humanos e de fauna, além de vestígios paleobotânicos tais quais sementes e carvões.

\subsection{Contexto geológico e arqueológico}

Itapeva encontra-se em uma região planáltica com cotas altimétricas elevadas, na qual o relevo suave do planalto de São Paulo dá lugar a uma morraria intensa com grandes desníveis altimétricos locais e litologia diversificada. O grupo Itaiacoca se estende NE-SW desde a região de Guapiara-Itapeva até Itaiacoca (PR) compondo cerca de 200 km de extensão e em média 20 km de largura (Sallun Filho 1999:4), a Formação Furnas se restringe-se ao cânion do Itanguá a e o Abrigo de Itapeva.

A caracterização geológica da área apresenta metavulcanitos, compostos por metabasaltos, metadiabásios, metagabros, metaconglomerados, quartzitos impuros, quartzo e metaarenitos (op. cit.), porém, na região ao norte da área de pesquisa, praticamente não ocorrem as mesmas formações rochosas (Souza \& Souza 2002). Sendo o relevo constituído por declividades muito menos movimentadas constituídas por relevo suave.

Segundo Ab’Saber (2010) a região de Itapeva pertence ao domínio dos planaltos das araucárias, de aproximadamente $400.000 \mathrm{~km}^{2}$ e está sujeita a climas subtropicais com inverno relativamente brando de altitude média, variando entre 850 a 1.300 metros, sendo revestida por bosques de diferentes densidades, incluindo mosaicos de pradarias mistas e bosquetes (op. cit.).

O cânion do Itanguá, local onde insere-se o Abrigo de Itapeva, alcança de 50 a 100 metros de profundidade, entre 100 a 800 metros de largura, local para onde confluem águas de vários córregos que caem do altiplano. Sua característica principal é que há um grande bloco de rocha destacado do paredão rochoso que acabou por formar uma segunda parede, oposta à 
escarpa, resultando em uma área delimitada de largura entre 4 e $7 \mathrm{~m}$, aberta nas duas extremidades (Aytai 1970).

As pesquisas mais detalhadas realizadas anteriormente às atuais etapas de escavação, renderam um rico detalhamento das manifestações artísticas que são compostas por porções de cúpulas, - sendo identificado pigmento vermelho e preto em 60 dessas - círculos e sulcos de profundidades e larguras diferentes. Essas figuras configuram os trabalhos de Aytai (1970) que priorizou a arte rupestre produzindo relevés em moldes de gesso e experimentações que replicaram as técnicas de gravuras aplicadas ao suporte rochoso.

Entre 2015 e 2016 foram realizadas três etapas de campo. As unidades de escavação foram pensadas de modo a estabelecer uma trincheira, denominadas C18, D18 e E18. Isoladamente no setor sul optou-se por realizar outra sondagem que recebeu o nome de G6. A escavação se deu por níveis artificiais com intervalos a cada $10 \mathrm{~cm}$ com fins de registro controlado, tal qual no Abrigo do Alvo.

Todas as amostras de carvão datadas são provenientes da unidade D18. A idade mais recuada do sítio foi obtida no nível 13, último nível da escavação quando se atingiu a base da unidade aos $130 \mathrm{~cm}$ de profundidade (Tabela 2).

Tabela 2. Amostras de $\mathrm{C}^{14}$ datadas para o Sítio Abrigo de Itapeva. Table 2. $\mathrm{C}^{14}$ dated samples from the Abrigo de Itapeva site.

\begin{tabular}{lccc}
\hline Amostra & Nível & Idade radiocarbônica convencional & Idade Calibrada \\
\hline Beta 432530 & 2 & $640 \pm 30 \mathrm{AP}$ & 645 a $585 \mathrm{cal}$. AP \\
Beta 432531 & 4 & $860 \pm 30 \mathrm{AP}$ & 770 a $675 \mathrm{cal}$. AP \\
Beta 432532 & 7 & $860 \pm 30 \mathrm{AP}$ & 770 a $675 \mathrm{cal}$. AP \\
Beta 432533 & 13 & $1470 \pm 30 \mathrm{AP}$ & 1365 a $1295 \mathrm{cal}$. AP \\
Beta 432534 & 13 & $4770 \pm 30 \mathrm{AP}$ & 5585 a $5505 \mathrm{cal}$. AP \\
\hline
\end{tabular}

\section{Definição dos atributos analisados no Abrigo do Alvo e Abrigo de Itapeva}

Como qualquer fenômeno a ser analisado os artefatos de pedra lascada possuem uma infinidade de variação morfológica e tecnológica. Os atributos elencados para a análise do material encontrado nos dos dois sítios, foram propostos para responder questões específicas de cada pesquisa, não sendo de modo algum uma definição universal de como se fazer análise de material lítico.

Por ora temos um quadro quantitativo e qualitativo, resultado de uma etapa inicial de identificação do material lítico. As análises do Abrigo do Alvo encontram-se um pouco adiantadas em relação ao Abrigo de Itapeva devido ao fato de ter sido escavado primeiro, portanto, alguns atributos elencados abaixo não constam da caracterização do Abrigo de Itapeva.

A ficha de análise consiste na observação de atributos contempla: 1) atributos genéricos: observação e identificação de matéria-prima, dimensões, peso, tipo de suporte, córtex, retoques e sinais de uso; 2) atributos de lascamento que revelam detalhes técnicos como: talão, bulbo, ângulo de lascamento, terminação da lasca e negativos de retirada e 3) os tipos de retoques e sinais de uso nas peças.

Tendo em vista que foram criadas classes que categorizam a análise, suas definições se tornam necessárias. A classe lasca é entendida como produtos de lascamento com caracteres técnicos particulares (Vialou 1980: 77). Lascas menores que $2 \mathrm{~cm}$ são consideradas microlascas (Morais 1987). Lascas fragmentadas se referem a parte proximal da lasca com a presença do talão (Inizan et al. 1999), por oposição, fragmentos de lasca será usado para designar a parte distal da peça (Morais 1987). 
Resíduo ou fragmento será entendido como uma peça quebrada não intencionalmente na oportunidade do destacamento do núcleo ou se refere a matéria-prima não modificada tecnicamente (Inizan et al. 1999). Por núcleo, entende-se um bloco de matéria-prima no qual as lascas, lâminas ou lamelas são destacadas para produzir suportes para artefatos (Inizan et al. 1999). Seixo lascado é considerado uma peça que apresenta estigmas de lascamentos iniciais (Inizan et al. 1999). Por fim, a categoria não antrópico se refere às peças coletadas nas unidades mas não apresentam nenhum sinal claro de lascamento intencional.

\section{Caracterização do material: Abrigo do Alvo}

A coleção apresenta 116 peças e foram determinadas 8 classes utilizadas para classificar a coleção lítica. (Tabela 3).

Tabela 3. Classes identificadas no Sítio Abrigo do Alvo.

Table 3. Abrigo do Alvo identified lithics categories.

\begin{tabular}{lcc}
\hline Classe & Quantidade & Porcentagem (\%) \\
\hline Fragmento de lasca & 15 & 12,93 \\
Lasca & 15 & 12,93 \\
Lasca menor que 2cm & 50 & 43,10 \\
Lasca fragmentada & 9 & 7,75 \\
Resíduo & 14 & 11,20 \\
Núcleo & 4 & 3,44 \\
Não antrópico & 9 & 7,75 \\
\hline Total & $\mathbf{1 1 6}$ & $\mathbf{1 0 0 \%}$ \\
\hline
\end{tabular}

Há uma variedade de matérias-primas encontradas no sítio que compreende na maioria sílex (62 peças $=54 \%$ ) e arenito silicificado $(40$ peças $=35 \%)$. Em baixas proporções foram identificados materiais em basalto $(5$ peças $=4 \%)$, quartzito $(5$ peças $=4 \%)$ e quartzo $(4$ peças $=3 \%)$.

A classe com maior número de material encontrada no sítio é lasca $<2 \mathrm{~cm}$ representando 43,1\% da coleção. Em seguida em mesma proporção foram identificadas lascas e fragmentos de lascas $12,93 \%$ seguido, também na mesma proporção, por lascas fragmentadas. Os materiais considerado como não antrópico refletem 7,75\%. Por fim, os núcleos aparecem em menor proporção representando 3,44\%. Destaca-se que não foi encontrado nenhum percutor.

Com exceção ao quartzo, todas as outras matérias-primas, apresentam sinais de queima em alguns materiais - que podem claramente ser notados por alteração na coloração ou marcas rugosas que causaram alteração na superfície da rocha. A ação térmica nas lascas não foi uma atividade intencional, visto que são encontradas marcas que comprovam uma falta de controle do calor como cúpulas e superfícies rugosas.

A tendência das lascas é apresentar talões lisos, ausentes de qualquer tipo de preparação. Na grande parte do material, os bulbos são salientes e únicos em cada lasca. Bulbos difusos e ausentes, que poderiam ser indicativos de percussão macia (Rodet \& Alonso 2004) também foram identificados, no entanto, com menor ocorrência

Com relação ao número de retiradas, foi identificada a tendência de serem obtidos três lascamentos na face externa. Essas retiradas produzem arestas que guiam a retirada seguinte, das quais poucas apresentaram fraturas em degrau.

Fraturas nas partes distais e proximais das lascas também foram identificadas, seja por excesso de energia na aplicação do golpe, por acidentes de lascamento, como fratura siret, ou por eventos pós-deposicionais. Quando a parte distal estava presente, foi possível identificar que a maioria apresenta uma terminação em gume. 
No que se refere à classe fragmentos de lasca, a matéria-prima se limita a sílex $(\mathrm{n}=8)$ e arenito silicificado $(\mathrm{n}=7)$. Quando possível, foi identificada a parte distal da lasca, que corresponde na maioria em terminações em gume, seguidas por fratura (Morais, 1987). A maioria apresenta quatro ou mais retiradas na face externa. Sobre o córtex 29\% apresentam superfícies decorrente de intemperismo físico e químico. Nenhum material apresentou sinal de queima.

As classes lasca e lasca fragmentada serão abordadas conjuntamente, pois ambas apresentam talão e bulbos intactos. A matéria-prima das lascas é composta por sílex $(\mathrm{n}=7)$ e arenito silicificado $(n=8)$. As lascas fragmentadas dividem-se entre arenito silicificado $(n=6)$, sílex $(\mathrm{n}=2)$ e basalto $(\mathrm{n}=1)$.

No que se refere à presença de córtex somente sete líticos apresentaram essa superfície que recobria menos de $50 \%$ da superfície. Desse total, duas exibem córtex obtido por ação fluvial, quatro apresentam uma superfície obtida por ação química e física (intemperismo) e uma peça apresenta pátina decorrente de queima.

Analisando os atributos de lascamento, foi possível notar que o talão predominante é do tipo liso. No entanto, também foi identificado talão parcialmente ausente - segundo mais recorrente - talões cortical e linear, não sendo identificado nenhuma preparação.

No que se referem às terminações, os bordos se apresentam em gume, seguidos por terminações refletidas. A maioria exibe mais do que três retiradas na superfície externa. Sinais de queima são notados. Acidentes de lascamento como fraturas siret também foram identificados, mas são poucos.

"Núcleo" - Dois núcleos são de arenito silicificado. O primeiro exibe cinco retiradas e encontra-se fragmentado, não apresenta superfície cortical e possui 49 x 46,5 x $25 \mathrm{~mm}$ de dimensão (comprimento, largura e espessura, respectivamente). O segundo é um núcleo sob lasca com que apresenta quatro marcas de retiradas na face externa da lasca, possuindo $115 \mathrm{x}$ 119 x 36 mm de dimensão.

Outros dois núcleos foram encontrados em quartzito e correspondem a dois seixos lascados. O primeiro apresenta duas retiradas e exibe toda superfície cortical obtida por ação fluvial com as dimensões de 67 x 94 x 64 mm. O segundo é um seixo bem menor com 31 x 28 x 19 mm e exibe uma retirada.

Os materiais não antrópicos representam 7,75\% $(n=9)$ da coleção. Compreende dois blocos - considerados matéria-prima bruta - e produtos de lascamento que não foram obtidos por ação humana, no entanto, sua presença na área do sítio é indicativa de que a matériaprima foi levada até o local, visto que não é natural da formação do abrigo, nessa perspectiva foi coletado um geodo de quartzo.

Todas as outras matérias-primas (sílex, basalto e arenito silicificado) apresentam sinais de queima que podem ser notados por alteração na coloração e pelos estigmas causados pelo aquecimento em excesso. Foi possível realizar a remontagem de duas peças que se encontram na mesma unidade mas em níveis distintos (3 e 4) com 10 cm de distância na vertical.

\section{Caracterização do material: Abrigo de Itapeva}

Até o momento, nove tipos de matérias-primas foram identificados, sendo: silexito (59\%), quartzo (23\%), arenito silicificado (8\%), rochas ígneas diversas (4\%), argilo-mineral (1\%), rochas metamórficas - xisto e quartzito (2\%), e rochas metapelíticas, argilitos (1\%). Desses 2.754 fragmentos de rochas recolhidos até a segunda etapa de escavação, $25 \%$ $(n=690)$ foram descartados em função das condições de queimas serem muito acirradas descaracterizando os estigmas de lascamento, sendo assim, 75\% ( $\mathrm{n}=2.064)$ da amostra foi analisada. No total a coleção apresenta 1.340 artefatos em lascas íntegras, lascas fragmentadas e fragmentos, a distribuição da frequência pode ser vista na Tabela 4. 
Tabela 4. Classes gerais identificadas no Sítio Abrigo de Itapeva.

Table 4. General identified categories from the Abrigo de Itapeva site.

\begin{tabular}{lllll}
\hline Classe & & Quantidade & $\begin{array}{l}\text { Porcentagem (\%) } \\
\text { classe }\end{array}$ & $\begin{array}{l}\text { Porcentagem (\%) } \\
\text { total }\end{array}$ \\
\hline Lasca íntegra & $<2 \mathrm{~cm}$ & 481 & $61 \%$ & \\
& $>2 \mathrm{~cm}$ & 303 & $39 \%$ & $55 \%$ \\
& Total (classe) & $\mathbf{7 8 4}$ & $\mathbf{1 0 0 \%}$ & \\
\hline Lasca fragmentada & $<2 \mathrm{~cm}$ & 293 & $75 \%$ & $27 \%$ \\
& $>2 \mathrm{~cm}$ & 97 & $25 \%$ & \\
& Total (classe) & $\mathbf{3 9 0}$ & $\mathbf{1 0 0 \%}$ & \\
\hline Fragmento de lasca & $<2 \mathrm{~cm}$ & 200 & $78 \%$ & $18 \%$ \\
& $>2 \mathrm{~cm}$ & 56 & $22 \%$ & $\mathbf{1 0 0 \%}$ \\
\hline Todos & Total (classe) & $\mathbf{2 5 6}$ & $\mathbf{1 0 0 \%}$ & \\
\hline
\end{tabular}

A quantidade de córtex nas peças é um indicativo do tipo de suporte, possíveis fontes de extração e podem expressar etapas de debitagem. Em 85\% dos casos em lascas íntegras elas apresentam entre 0 a 25\% de córtex, enquanto que nas lascas fragmentadas, com a informação de que a porção cortical pode ter sido destacada no ato da quebra apresentam entre 0 a $25 \%$, somando 91\% dos casos. Deste modo, é possível afirmar que não estamos em etapas de debitagem cuja reserva cortical é presente, indicativo que os suportes ou são pequenos ou não são preparados inicialmente no sítio.

Nota-se que a característica predominante no Abrigo do Itapeva são lascas $<2 \mathrm{~cm}$ (Tabela 4). São condizentes com etapas de finalizações de artefatos. O peso equivale em gramas a porções muito leves que podem variar entre 1,83 g em média para lascas íntegras e 4,24 g para lascas fragmentadas, lembrando que estas abarcam a maior parcela de matériasprimas pouco transformadas, notadamente as rochas ígneas.

Por fim os sinais de uso também considerados alterações de superfície, apontam para características relacionadas à formação do sítio na qual pode se notar um alto índice de queima: 52\% em lascas fragmentadas e 32\% em lascas íntegras.

Outras características significativas são discretas. Em lascas fragmentadas, marcas de uso e materiais agregados à superfície como óxido de ferro somam apenas $2 \%$, enquanto em lascas íntegras destaca-se mesmo que em discreta significância a presença de tratamento térmico em quartzo em $1 \%$ da amostra.

É relevante a quantidade de fragmentos que não possuem quaisquer sinais de uso correspondendo a $45 \%$ para lascas fragmentadas e $64 \%$ para lascas completas. Isto aponta que as lascas não são confeccionadas para uso in situ com aproveitamento de bordo cortante, mas participam de uma Cadeia Operatória que privilegia processos técnicos em que são parte de produção de artefatos.

Ressalta-se que lascas fragmentadas preservam intactos talão e bulbo de modo que é possível analisá-las conjuntamente com as lascas íntegras. Talões lisos representam $58 \%$ da amostra em lascas inteiras e $61 \%$ em lascas fragmentadas. Outras categorias também são encontradas como: cortical $9 \%$, linear $17 \%$, puntiforme $5 \%$, facetado $5 \%$, esmigalhado $6 \%$ e menos que 1\% talões diedros. Enquanto que os talões das lascas fragmentadas são corticais $8 \%$, lineares $22 \%$, puntiforme $5 \%$, facetados $3 \%$, esmigalhados $1 \%$ e outros que apresentam frequências inferiores a $1 \%$.

A estes fatores da técnica de produção de talão somam-se as técnicas de preparo do talão. Nas lascas íntegras os talões sem preparo somam 50\% da amostra, enquanto nas lascas 
fragmentadas somam $49 \%$, a presença de lábio é notada em $7 \%$ dos casos em lascas íntegras e $8 \%$ em lascas fragmentadas, indícios de abrasivo na cornija são respectivamente $18 \%$ e $15 \%$, enquanto retiradas formativas que preparam a face externa da lasca a partir de pequenas retiradas rente ao talão que modificam a curvatura da lasca representam $25 \%$ dos casos em lascas íntegras e $28 \%$ dos casos em lascas fragmentadas.

Lascas com abrasivo, lábio e retiradas formativas somam $50 \%$ dos casos em lascas integras e $51 \%$ dos casos em lascas fragmentadas de modo que metade da amostra avaliada apresenta algum tipo de cuidado técnico referente ao preparo do talão. O uso de abrasivo e lábio somam $25 \%$ em lascas íntegras e $23 \%$ em lascas fragmentadas e pode indicar o uso de percutor brando. Com isto, observa-se que a percussão dura é predominante, contudo há evidências de que percutores brandos podem estar sendo usados pelo menos em $25 \%$ dos casos somando-se abrasivos e lábio conjuntamente com a avaliação que não há fissuras próximas ao talão nestas peças.

O número de retiradas é esclarecedor sobre as etapas de início, meio e fim de obtenção de artefatos. Em lascas íntegras $75 \%$ apresentam apenas 1 cicatriz de retirada e nas lascas fragmentadas naquelas em que pode-se observar seguramente os estigmas de lascamento, 91\% apresentam apenas 1 cicatriz de lascamento. Deste modo o máximo de retiradas que são observadas são três, seguindo na maioria dos casos o eixo de debitagem.

\subsection{Artefato retocado}

O artefato foi coletado em superfície (Figura 3). Caracteriza-se por ser produzido sobre lasca. Suas medidas foram tomadas em relação ao eixo morfológico, sendo respectivamente 7,5 cm de comprimento, 5,7 cm de largura e 2,5 cm de espessura. Não há qualquer reserva cortical na peça, observando-se que lascas quadráticas advindas de retiradas com poucas cicatrizes na face externa, no caso apenas duas estão presentes.

Nota-se que as cicatrizes de retiradas na superfície dorsal da peça é a primeira sequência operacional da produção do artefato que relaciona-se com etapas de debitagem anterior ao processo de retoque. Entretanto, modificações secundárias ocorrem na superfície dorsal, próxima à porção distal, na qual há uma retirada longitudinal advinda da aresta lateral com a intenção de adelgaçamento da peça provocando concavidade.

A segunda sequência transformativa da peça está contida no dorso esquerdo em que nove retiradas longitudinais, sequenciais, contínuas e proporcionais em termos de tamanho e largura, medindo $1,4 \mathrm{~cm}$ em média, com $70^{\circ}$ de inclinação fornecem uma área de preensão, sendo uma área transformativa importante de sequências de retoques que modificam esta porção. Ainda nesta área, rente ao gume, em suas margens há retoques sequências contínuos, com orientação paralela, sem alternância das retiradas na face ventral, com o ângulo de retoque mensurado em $80^{\circ}$.

Após os aspectos transformativos há uma série de sinais de uso fazendo com que parte dos retoques fossem reavivados ou desgastados perdendo sua caracterização morfológica. No dorso lateral direito seguindo o eixo morfológico da peça a série de retoques se concentra apenas na margem do artefato com retoques côncavos, de orientação paralela, sequência contínua e irregular que mede em média $0,1 \mathrm{~cm}$, apresenta alternância de retoques em relação a face ventral, sendo estes côncavos, descontínuos e concentrados no centro do artefato.

A extremidade proximal da peça, encontra-se quebrada, enquanto na porção distal há modificações secundárias importantes com retiradas em média de 0,6 cm, paralelas, contínuas e retilíneas. Aplicadas acima delas existe uma série de retoques contínuos, côncavos e irregulares concentrados na margem. Percebe-se como terceiro passo de ação sobre o artefato uma série de desgaste causado por uso e consequentemente modificação da morfologia delineada pelos retoques aplicados. 

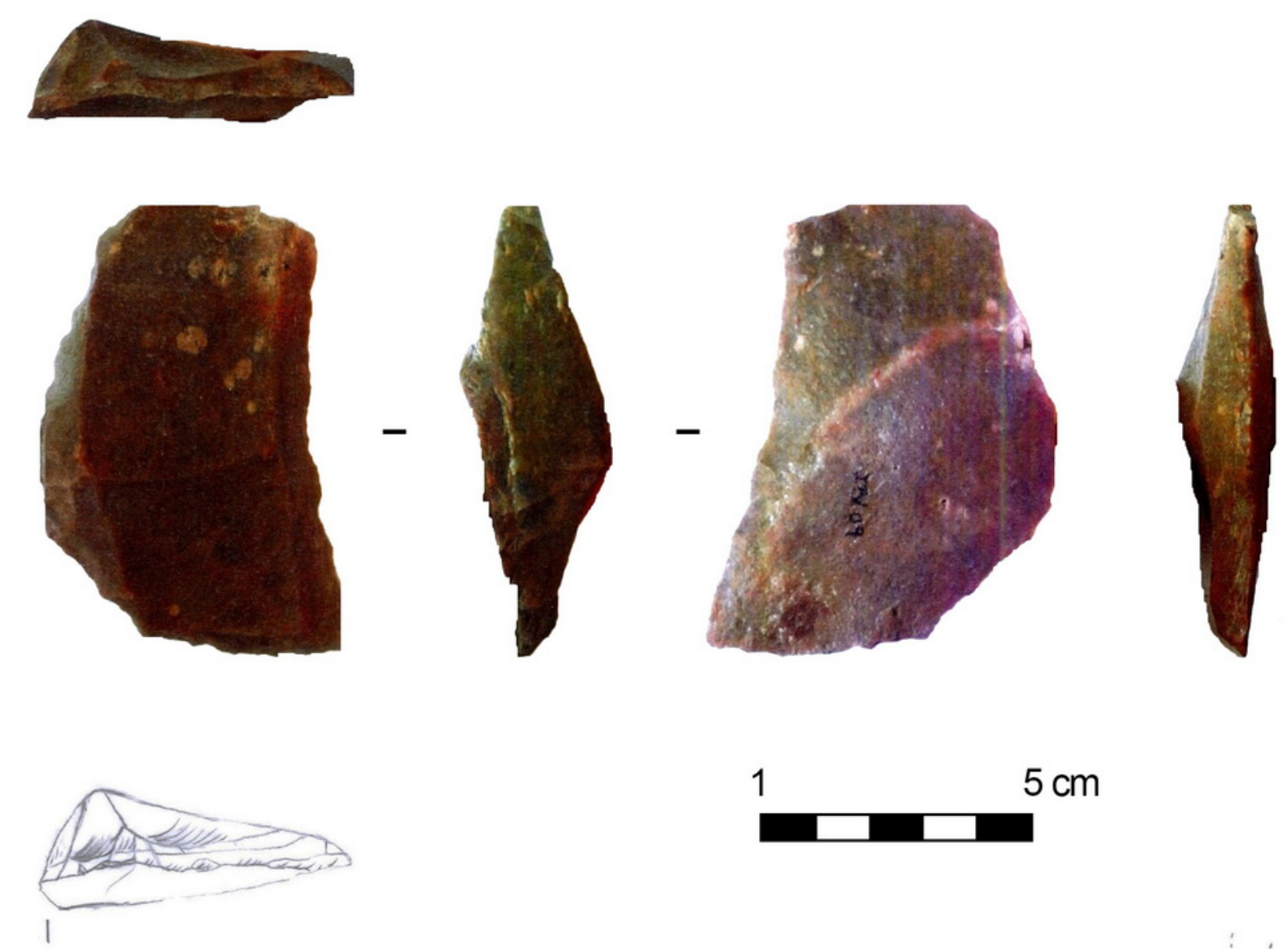

1
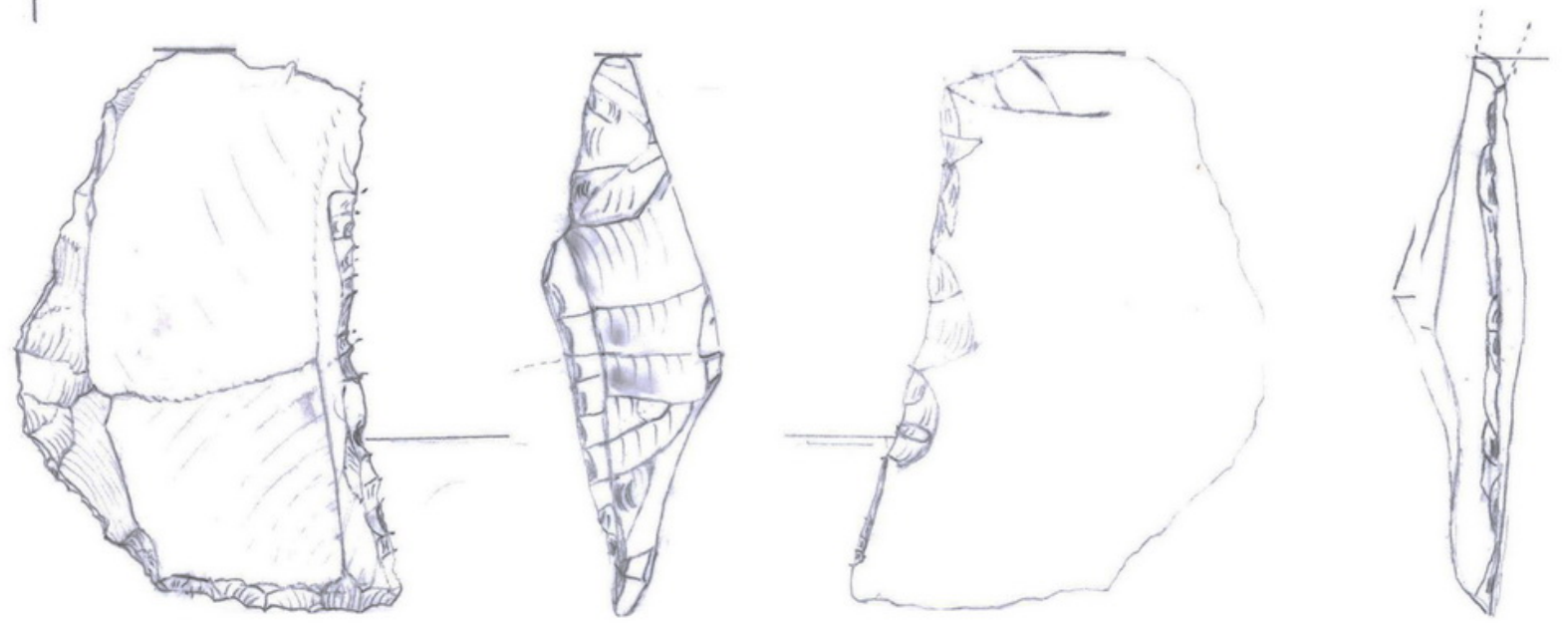

Figura 3: Artefato lítico retocado, sítio arqueológico Abrigo de Itapeva. Foto e desenho: Tatiane Souza (2017). Figure 3. Reotuched lithics artifact from the Abrigo de Itapeva archaeological site. Photo and drawing: Tatiane Souza (2017).

Em síntese a sequência de formatação do artefato é o destacamento de um núcleo de lascas quadráticas, com poucas cicatrizes na face dorsal, aplicando no dorso esquerdo uma série de retoques retilíneos e alongados seguidos por retoques marginais curtos e alternados no dorso direito. Por fim há uma série de retoques na porção distal que produz concavidade e acima destes, retoques curtos que modificam apenas a margem do artefato. Após ações secundárias notam-se sinais de uso e desgaste. 


\section{Resultados parciais e considerações contextuais acerca dos sítios Abrigo do Alvo e Abrigo de Itapeva}

Grupos caçadores-coletores ocuparam a região de Rio Claro tanto em sítios abrigados quanto em sítios a céu aberto. Miller (1969) estudou os extratos arqueológicos da região na tentativa de interpretar as ocupações. De acordo com suas considerações, o grande número de sítios arqueológicos significaria uma intensa ocupação da área (Miller 1972) e não ocupações rápidas que indicariam "pouso para sortida de caça” (Altenfelder 1968).

Tradições e fases foram elaboradas por Miller (1972) na tentativa de interpretar a variabilidade das indústrias líticas que compreendem artefatos polidos e lascados como pontas bifaciais e plano-convexos. No caso do Abrigo do Alvo a análise leva em consideração as datações e os resultados de pesquisas anteriores para pensar em questões de similaridades tecnológicas, tentando delinear um quadro de dispersão de grupos caçadores-coletores durante o Holoceno médio.

A coleção analisada aponta uma indústria unifacial que a partir da percussão direta, com percutor duro, obtinham lascas com gumes cortantes que possivelmente seriam utilizadas como instrumentos. Não foi encontrado durante a escavação nenhum artefato formal, como plano-convexo ou bifacial, como é o caso de sítios no encontrados na mesma região (Collet 1982; Caldarelli 1983).

A análise do material, até então, também não permitiu a identificação de manufatura de artefatos formais. No entanto, a ausência dessas ferramentas no sítio não implica que elas não existam. É necessário considerar que houve apenas uma curta e única etapa de escavação que gerou uma amostra de vestígios líticos pouco densa. Desse modo, a coleção pode não ser representativa da ideia geral dessa a indústria.

Por outro lado, no Abrigo de Itapeva levando-se em consideração os mesmos fatores elencados para o abrigo do Alvo, (tecnologia e cronologia) é possível vislumbrar um horizonte ceramista bem delimitado com uma tecnologia de produção de lascas oriundas de artefatos formais, caso atípico e mais similar a períodos mais recuados inserido no holoceno médio.

A data mais recuada obtida na base do abrigo nos faz pensar na possibilidade de correlações com indústrias líticas de áreas adjacentes que apresentam mesma cronologia e devem ser exploradas segundo a possibilidade de notificação de relações técnicas e servir de parâmetros para tecer compatibilidade ou incompatibilidade também com o Abrigo do Alvo localizado em outra região do estado.

Dada as categorias de análise entre os dois Abrigos, o primeiro item a ser destacado é que há uma grande divergência no que se refere à quantidade de peças de cada coleção. A caracterização do sítio Abrigo do Alvo se limita a poucas peças, ao contrário do Abrigo de Itapeva que possui uma amostragem considerável.

A caracterização tecnológica do Abrigo do Alvo refere-se a percussão dura com retirada "simples", predominância de talões lisos, corticais e lineares. No Abrigo de Itapeva a caracterização tecnológica apresenta certa similaridade e discordância em relação aos estigmas de lascamento encontrados no Abrigo do Alvo.

Embora haja predominância de talões lisos, há porcentagem considerável de outros tipos de talões e um investimento considerável na preparação dos mesmos sejam eles corticais, lineares, facetados e etc. Identifica-se princípios de lascamento condizentes com percutores brandos como a presença de lábio, ausência de esquilha bulbar e abrasivo de cornija, uma evidência que pode estar presente também em percutores duros tal qual bulbo difuso (Ekshtain 2006; McPherron 2007; Toth \& Schick 2009).

A curiosidade refere-se ao fato de que o Abrigo de Itapeva mantém um quadro cronológico em sua grande maioria mais recente que o Abrigo do Alvo, apresentando uma 
inserção no período ceramista e uma única data recuada contida na base da quadra D18, mas que, no entanto, estigmas técnicos diferenciados estão presentes em todos os níveis estratigráficos sendo esta uma questão a ser explorada. Desta forma ainda é prematuro tecer relações entre o Abrigo do Alvo e de Itapeva em relação a tecnologia, de modo que o Abrigo de Itapeva apresenta características similares ao Alvo mas vão além delas, podendo tratar-se de um viés amostral que deve a seu tempo ser esclarecido por novas escavações na área de Analândia.

Por fim consideraremos algumas questões referentes as matérias-primas e a similaridade ou não em relação aos dois abrigos.

O arenito silicificado aparece em ambos os sítios, mas são de formações geológicas diferentes, o que o confere a ele diferente aptidão ao lascamento. $\mathrm{O}$ arenito silicificado no abrigo do Alvo é a segunda matéria-prima mais expressiva, enquanto em Itapeva é a terceira. Nesta matéria-prima no abrigo de Itapeva nota-se maior presença de córtex que serviria de suporte para manufatura de artefatos, enquanto no Abrigo do Alvo os arenitos exibem sinais claros de lascamento, mas não considerados suporte de instrumento, visto que terminado em gume essas lascas já serviriam como ferramenta.

O sílex se manifesta como a matéria-prima principal em ambos os sítios, seja apenas para a obtenção de gumes cortantes, como é o caso do Abrigo do Alvo ou no Abrigo de Itapeva com sinais mais abrangentes de preparo técnico. A discrepância mais evidente é relativa a quantidade de quartzo, discreta no Abrigo do Alvo e abundante em Itapeva.

Dada estas considerações é possível afirmar por enquanto pouca similaridade entre o Abrigo do Alvo e o Abrigo de Itapeva. As discrepâncias referem-se talvez a um contexto regional de captação de matérias-primas e viés amostral que pode ser suprido com futuras intervenções e a continuidade do deslindamento das características técnicas nos dois sítios.

\section{Agradecimentos}

Gostaríamos de agradecer a Coordenação de Aperfeiçoamento de Pessoal de Nível Superior (CAPES). Ao Prof. Dr. Astolfo Araujo pelo convite em participar das etapas de escavação desses sítios que pertencem aos projetos “A ocupação Paleoíndia no Estado de São Paulo: uma abordagem geoarqueológica” (FAPESP 2016/23.584-6) e “Arqueologia ItararéTaquara no extremo sul de SP: Investigação da complexidade cronocultural entre abrigos rochosos, estruturas subterrâneas e montículos de terra na região de Itapeva” (Chamada Universal MCTI/CNPq N ${ }^{\circ}$ 1/2016).

\section{Referências}

Ab’Saber, A. N. 2010. A organização natural das paisagens inter e subtropicais brasileiras. In: A obra de Aziz Ab'Saber (Modenesi-Gaiterri, M.C., Bartorelli, A., Mantesso-Neto, V., Carneiro, C. dal Ré, Andrade de Lima, M.B., Eds.), Beca-Ball Edições Lisboa, São Paulo: p. 1-14. (em português) (“The scientific work of Aziz Ab’Saber”)

Alberto, L. A. 2013. Redescoberta Rupestre: São Paulo e um novo cenário. Revista de Arqueologia, Parte 3 - A Construção de Interlocutores: campos disciplinares e sociedade, 27(1): 157-158. (em português) ("Rediscovered rock art: São Paulo and a new scenario") doi:10.24885/sab.v26i2/1.387

Altenfelder, F. S. 1968. Arqueologia Pré-Histórica da região de Rio Claro. In: Pré-História Brasileira (XIX), (XIX Reunião Anual da Sociedade Brasileira pelo Progresso da Ciência) (Duarte, P., Ed.), Instituto de Pré-História da Universidade de São Paulo, São Paulo: 157-166. (em português) ("Prehistoric archaeology from Rio Claro region”) 
Araripe, T. A. 1887. Cidades Petrificadas e Inscrições Lapidares no Brasil. Revista Trimensal do Instituto Histórico e Geográfico Brasileiro, 50: 213-294. (em português) ("Petrified cities and lapidary inscriptions in Brasil”)

URL: https://archive.org/details/CidadesPetrificadasEInscripcoesLapidaresNoBrazil

Araujo, A.G.M. 2001, Teoria e método em arqueologia regional: um estudo de caso do Alto Paranapanema, Estado de São Paulo. Tese de Doutorado. Faculdade de Filosofia, Letras e Ciências Humanas, Universidade de São Paulo, São Paulo, 341 p. (em português) ("Theory and method in regional archaeology: A case study from upper Paranapanema, São Paulo State”) doi:10.11606/t.8.2001.tde-17122013-093345

Araujo, A.G.M. 2008. Geoarqueologia em sítios abrigados: processos de formação, estratigrafia e potencial informativo. In: Geoarqueologia: teoria e prática (Rubin, J.C., Silva, R.T., Eds.), Editora da Universidade Pontifícia de Goiás, Goiânia: p. 72-88. (em português) ("Geoarchaeology in sheltered sites: Formation processes, stratigraphy and informative potential”)

Araujo, A.G.M. 2012, Relatório Final de Atividades. A ocupação Paleoíndia no Estado de São Paulo: Uma abordagem geoarqueológica, Projeto FAPESP 2009/54720-9. São Paulo, 246 p. (em português) ("Final activities report")

Araujo, A.G.M; Correa, L. C. 2016. First notice of a Paleoindian site in central São Paulo State, Brazil: Bastos site, Dourado County. Palaeoindian Archaeology, 1(1): 4-14. ("Nota prévia sobre um sítio Paleoíndio no centro do Estado de São Paulo, Brasil: Sítio Bastos, cidade de Dourado")

URL: http://journals.kvasirpublishing.com/pa/article/view/17

Aytai, D. 1970. As gravações rupestres de Itapeva. Revista da Universidade Católica de Campinas, 14(33): 29-61. (em português) ("The rock art engravings from Itapeva”)

Caldarelli, S.B. 1983, Lições da pedra: aspectos da ocupação pré-histórica no vale médio Rio Tietê. Tese de Doutorado. Faculdade de Filosofia, Letras e Ciências Humanas. Universidade de São Paulo, São Paulo, 355 p. (em português) ("Stone lessons: Aspects of the middle Tietê river prehistoric occupation”)

Collet, G.C. (1980), Considerações sobre algumas peças líticas de Pavão (Itaoca-Apiaí-SP). Não publicado. Relatório. Departamento de Arqueologia da Sociedade Brasileira de Espeleologia, São Paulo, 19 p. (em português) ("Considerations on some lithics pieces from Pavão (Itaoca-Apiaí-SP”)

Collet, G.C. 1981. Relatório de Prospecção em Analândia-SP. Relatório de Atividades. Grupo Bagrus de Espeleologia, São Paulo, 11 p. (em português) ("Report of survey in Analândia, SP”)

Collet, G.C. 1982, Relatório de Prospecção em Analândia-SP. Relatório de Sondagem. Grupo Bagrus de Espeleologia, São Paulo, 25 p. (em português) ("Report of survey in Analândia, SP. Survey report”)

Collet, G. C. 1994, Proteção Rupestre. InformATIVO SBE. Sociedade Brasileira de Espeleologia, Campinas, 10 p. (em português) ("Rock art protection”)

DeBlasis, P. A. D. 1988, A ocupação colonial do Vale do Ribeira de Iguape, SP: os sítios líticos do médio curso. Dissertação de Mestrado, Faculdade de Filosofia e Ciências Humanas, Universidade de São Paulo, São Paulo, 178 p. (em português) ("The colonial occupation of the Ribeira de Iguape Valley, SP: The lithic sites of the middle course”) 
DeBlasis, P. A. D. 1996, Bairro da Serra em três tempos: arqueologia, uso do espaço regional e continuidade cultural no médio Vale do Ribeira. Tese de Doutorado, Faculdade de Filosofia, Letras e Ciências Humanas, Universidade de São Paulo, São Paulo, 166 p. (em português) ("Bairro da Serra in three times: Archaeology, use of space and cultural continuity in the middle Ribeira Valley")

Ekshtain, R. 2006. A comparative study of knapping accidents in the Levantine Mousterian. Master's thesis. Institute of Archaeology, Hebrew University of Jerusalem, Jerusalem, 108 p. (em inglês) ("Estudo comparativo dos acidentes de lascamento no Levantino Mosteriense")

Ferreira, R.V. 2005. Utilização de Sistemas de Informações Geográficas na Identificação de Unidades Geoambientais no Município de Analândia - SP. Dissertação de Mestrado. Instituto de Geociências, Universidade Estadual de Campinas, Campinas, 120 p. (em português) ("GIS using in geoambiental unities identification in Analândia municipality, SP”).

Instituto de Pesquisas Tecnológicas (IPT) 1981, Mapa geomorfológico do Estado de São Paulo. Escala 1.500.000. Divisão de Minas e Geologia Aplicada, Instituto de Pesquisas Tecnológicas do Estado de São Paulo, São Paulo. (em português) (“Geomorfological map of São Paulo State”)

Inizan, M-L; Reduron-Ballinger, M.; Roche, H; Tixier, J. 1999, Technology of knapped stone: Followed by a multilingual vocabulary Arabic, English, French, German, Greek, Italian, Portuguese, Spanish. Traduzido por Féblot-Augustins. Préhistoire de la pierre tailléé Vol. 5, Cercle de Recherches et d'Etudes Préhistoriques (CREP), Nanterre, 191 p. (“Tecnologia das pedras lascadas: acompanhado por um vocabulário multilíngue em árabe, inglês, francês, alemão, grego, italiano, português, espanhol”)

Leite, S.S. 2002. Análise ambiental da área do morro do Cuscuzeiro (Analândia, SP) como subsídio ao planejamento ambiente local. Dissertação de Mestrado. Centro de Ciências Biológicas e da Saúde, Programa de Pós Graduação em Ecologia e Recursos Naturais, Universidade de São Carlos, São Carlos, 149 p. (em português) ("Environmental analysis of the hill area of Cuscuzeiro (Analândia, SP) as subsidy to local environmental planning”)

Kamase, L.M. 2004. Casas subterrâneas e feições doliniformes: um estudo de caso na bacia do Alto Taquari (SP). Dissertação de mestrado. Faculdade de Filosofia, Letras e Ciências Humanas. Universidade de São Paulo, São Paulo, 96 p. (em português) ("Pit houses and doliniform features: A case study in the Alto Taquari basin (SP)”)

McPherron, S.P (Ed.). 2007. Tools versus cores. Alternative approaches to Stone Tool Analysis. Cambridge Scholar Publishing, Cambridge, 277 p. ("Ferramentas versus núcleos. Abordagens alternativas para análises de ferramentas de pedra”)

Miller Jr, T. O. 1969. Sítios Arqueológicos da Região de Rio Claro Estado de São Paulo. Faculdade de Filosofia Ciências e Letras de Rio Claro, São Paulo, 81 p. (em português) (“Archaeological sites from Rio Claro region, São Paulo state”)

Miller Jr, T.O.1972. Arqueologia da Região Central do Estado de São Paulo. Dédalo, 16: 13118. (em português) ("Archaeology of the central region of São Paulo State”)

Pallestrini, L. 1969. Sítio Arqueológico Fonseca. Revista do Museu Paulista, 19: 5-104. (em português) ("The Fonseca archaeological site”). 
Pallestrini, L. 1975. Interpretações de estruturas arqueológicas em sítios do estado de São Paulo. Coleção Museu Paulista, Serie de Arqueologia, 1: 208 p. (em português) ("Interpretations of archaeological structures in sites in the state of São Paulo")

Pallestrini, L.; Chiara, F. 1978. Indústria lítica do sítio Camargo 76: município de Piraju, Estado de São Paulo. Coletânea de estudos em homenagem a Annete LamingEmperaire. Coleção do Museu Paulista. Série Ensaios, 20:83-122 (em português) ("The lithic industry of Camargo 76 site: Piraju Municipality, State of São Paulo”)

Prous, A. 1979. Première information sur les maisons souterraines de l'état de São Paulo, Brésil. Revista de Pré-História, 1: 127-145. (em francês) ("First information about pit houses in the state of São Paulo, Brazil”)

Prous, A. 1991. Arqueologia Brasileira. Editora Universidade de Brasília, Brasília, 613 p. (em português) ("Brazilian archaeology")

Robrahn, E.M. 1988. A ocupação pré-colonial do vale do rio Ribeira de Iguape, SP: os grupos ceramistas do médio curso. Dissertação de Mestrado, Faculdade de Letras, Filosofia e Ciências Humanas, Universidade de São Paulo, São Paulo, 227 p. (em português) ("The precolonial occupation of Ribeira do Iguape river valley, SP: The ceramic groups of the middle course")

Morais, J.L. 1987. A Propósito do Estudo das Indústrias Líticas. Revista do Museu Paulista, 32: 155-184. (em português) (“About study of lithic industries”)

Rodet, J; Alonso, M. 2004. Princípios de reconhecimento de duas técnicas de debitagem: percussão direta dura e percussão direta macia (tendre): experimentação com material do norte de Minas Gerais. Revista de Arqueologia, 17: 63-74. (em português) ("Principles of recognition of two debitage techniques: Hard direct percussion and soft direct percussion: Experimentation with northern Minas Gerais state material”) doi:10.24885/sab.v17i1.192

Sallun Filho, W. 1999. Análise dos estromatólitos do grupo Itaiacoca (Proterozóico) ao sul de Itapeva, SP. Dissertação de Mestrado, Instituto de Geociências da Universidade de São Paulo, Universidade de São Paulo, São Paulo, 126 p. (em português) (“Analysis of the stromatolites from the Itaiacoca group (Proterozoic) in the south of Itapeva, SP”)

Souza, C.R.G., Souza, A,P. 2002. O escarpamento estrutural Furnas na região S-SE do Brasil. Sítios geológicos e paleontológicos do Brasil, Vol. 1 (Schoblenhaus, C., Campos, P.A., Queiroz, E.T., Winge, M., Berbet- Born, M., Eds.), Comissão Brasileira de Sítios Geológicos e Paleontológicos (SIGEP), Brasília: p. 299-306 (em português) ("The Furnas structural escarpment in the S-SE region of Brazil”)

Vialou, A.V. 1980. Tecno-Tipologia das indústrias líticas do sítio Almeida em seu quadro natural, arqueo-etnológico e regional. Universidade de São Paulo, Museu Paulista, Instituto de Pré-história, São Paulo, 170 p. (em português) (“Tecnotipology of the Almeida site lithic industries in its natural, archaeoethnological and regional context”)

Vialou, A.V. 1983. Brito: o mais antigo sítio arqueológico do Paranapanema, estado de São Paulo. Revista do Museu Paulista: nova série, 29: 9-21. (em português) ("Brito: The oldest site in Paranapanema, São Paulo state”)

Toth, N, Schick, K. 2009, The importance of actualistic studies in early Stone Age research: Some personal reflections. In: The cutting Edge: New approaches to the archaeology of Human Origins (Thot, N, \& Schick, K., Eds.), Stone Age Institute Publications Series 
Vol. 3, Stone Age Institute Press, Bloomington: p. 267-344. (“A importância dos estudos atualísticos na pesquisa inicial da Idade da Pedra: algumas reflexões pessoais”)

Troncoso, L.P.S. 2016. Paleoíndios em São Paulo: nota a respeito do sítio Caetetuba, Município de São Manuel, SP. Palaeoindian Archaeology, 1(1): 50-71. (em português) ("Paleoindians in São Paulo State: Notes related to the Caetetuba site, São Manuel municipality, São Paulo State”)

URL: https://journals.kvasirpublishing.com/pa/article/view/14/ 


\title{
Informative potential of two rockshleter sites in São Paulo state: Abrigo do Alvo and Abrigo de Itapeva
}

\author{
Letícia Cristina Correa, Tatiane Souza \\ Universidade de São Paulo. Av. Prof. Almeida Prado, 1466, Butantã, São Paulo, 05508-070, Brazil. \\ Email: Correa: leticiacorrea@usp.br; Souza: tatiane.souza@usp.br
}

\begin{abstract}
:
The state of São Paulo is a favorable area for karst formation. This occurs due to its geomorphology that presents lithological characteristics that favor the formation of caves and shelters in sandstone and limestone. Whether by speleologists or archaeologists, many archaeological sites in sheltered contexts have been discovered in the interior of São Paulo, however, their studies have not yet been developed in this state. This article presents preliminary results of research at two sites in shelter contexts - that is, the Alvo Shelter [Abrigo do Alvo], locating in Analândia (SP), with the most recent chronology established at $970 \mathrm{cal}$. years BP and the oldest at 7,500 cal. years BP; and the Itapeva Shelter [Abrigo de Itapeva], located in the municipality of the same name, with a more recent occupation around 585 cal. years BP and the oldest being around 5,858 cal. years BP. Both sites have similar archaeological remains which are usually found in sheltered contexts: rock art, faunal material, and lithics artifacts. In this case, we have an exception in the Itapeva Shelter, which in addition also contains some fragments of human bones and ceramic material that was originally associated with the Itarare tradition, being comprised of small, thin vessels with little variation in shape, usually without decoration, and presenting colors between dark brown, gray and black. Although the diversity of remains is remarkable, this paper will deal only with the lithic industries which are in the process of analysis at both sites. In order to establish comparisons between the sites, the research team initially sought to recognize generic characteristics such as raw material, support, dimensions, and others. In addition to this, technological attributes were observed in order to extract information about the kind of flintknapping, use-wear traces and retouching. We do not disregard the other evidence, such as rock art as a clue that possibly indicates cultural difference, nor the presence of pottery in the Itapeva Shelter site which is an indication that the inhabitants of this area already had other technology that went beyond the use of stone tools. Although the analysis is not over, some differences already stand out, for example, different raw materials used in the manufacture of stone artifacts have been observed at both sites, as well as the techniques of flaking, which in the Alvo Shelter were much more simplistic and absent of any retouching, and in the Itapeva Shelter where materials associated with several stages of reduction have been noticed along with with the presence of some retouched artifacts. Despite the noted differences, one cannot disregard the fact that the sample of the first site is much smaller when compared to the second one. This is due to the fact that a single fieldwork season was carried out at the first site while three excavations were made at the second. Although this is one reason, one must also consider that the material density in the Itapeva Shelter is much higher when comparing the number of pieces per excavation unit. Lastly, the analysis of the
\end{abstract}


lithic assemblages will continue but already they exhibit little similarity, thus supporting the hypothesis that we are not dealing with similar groups.

Keywords: São Paulo state; Holocene; rockshelters; lithics; technology 